\title{
Discourse Markers and Reading Comprehension: Is there an effect?
}

\author{
Mansoor Al-Surmi \\ The English Department, Northern Arizona University, Flagstaff, USA \\ Email:maa93@nau.edu; mansormi75@yahoo.com
}

\begin{abstract}
This paper is a contribution to the studies conducted for investigating the relationship between text linguistic signals and reading comprehension. The aim of this paper is to test the hypothesis that discourse markers facilitate reading comprehension. The specific question addressed is whether the presence of discourse markers facilitates reading comprehension at a global level (i.e., at the discourse level). Two groups of L2 learners were given a text followed by multiple choice comprehension questions. One group was given the actual text, while the other group was given the same text with discourse markers removed. The results indicated that there were no differences in the performance of the two groups. The study concluded that presence or absence of discourse markers may have no effect on the overall representation of coherent information needed for reading comprehension.
\end{abstract}

Index Terms-reading comprehension, discourse markers, local and global coherence, on-line and off-line coherence

\section{INTRODUCTION}

Reading comprehension is an outcome of text processing that involves the construction of a coherent cognitive representation of the information in the text. That representation is established by integrating the information provided in text units and understanding the coherence relations that bond those text units to each other (Dijk \& Kintsch, 1983). Cohesion, according to Halliday and Hasan (1976), are realized through four main elements: connectives such as conjunctions and some lexical expressions, cataphoric and anaphoric references, substitution as in using pronouns instead of nouns, and ellipsis. These features act together to structure text information in a coherent way for readers.

The relationship between reading comprehension and textual signals such as connectives, paragraph headings, and lexical signals, has been the topic of many studies (e.g. Chung, 2000; Degand, Lefèvre \& Bestgen, 1999; Degand \& Sanders, 2002; Geva, 1992; Loman \& Mayer, 1983; Millis, Graesser, \& Haberlandt, 1993; Millis \& Just, 1994; Noordman, Vonk, \& Kempff, 1992; Sanders \& Noordman, 2000; Spyridakis \& Standal, 1987). Such signals are claimed to positively or negatively affect the comprehension of text information at different levels: macrostructure and microstructure (Chung, 2000), local and global (Degand \& Sanders, 2002), on-line and off-line (Degand \& Sanders, 2002; Noordman et al., 1992; Sanders \& Noordman, 2000), and more on a pyramid ladder; intrasentential, intersentential and discourse (Geva, 1992; Millis \& Just, 1994). This paper is mainly concerned with the relationship between connectives and text comprehension at a global level which refers to the intellectual understanding of the overall connotation in a piece of discourse.

Connectives have been also called conjunctive expressions (Halliday \& Hasan, 1976), pragmatic markers (Fraser, 1990), discourse connectives (Blakemore, 1987), and widely in the field of memory and comprehension, lexical signals. Because of the variant names given to this category of linguistic forms, the term discourse markers will be used in this paper as a synonym to all terms above, as it has been now more likely to appear in recent research as prototype term to include any lexical form that has the function of connecting segments of text (e.g. Blakemore, 2002; Schiffrin, 2005; Taboada, 2006). Thus, the definition of discourse markers this paper is working under is as follow:

"I define discourse markers as a class of lexical expressions drawn primarily from the syntactic classes of conjunctions, adverbs, and prepositional phrases. With certain exception, they signal a relationship between the interpretation of the segment they introduce, S2, and the prior segment, S1. They have a core meaning, which is procedural, not conceptual, and their more specific interpretation is 'negotiated' by the context, both linguistic and conceptual" (Fraser, 1999, p. 931)

\section{A. Local and Global Coherence}

Although several studies have investigated the role of discourse markers in establishing a coherent discourse representation, there is still no consensus on whether discourse markers facilitate reading comprehension or not. Chung (2000) explored the contribution of discourse markers and paragraph headings to the macro and micro levels of comprehension. Three groups of different reading abilities were organized and given four reading tasks versions, one of them included no discourse markers. The study showed that discourse markers enhance the understanding of the overall 
representation of the information in a given text, i.e. at macrostructure level of reading, but having no effect at the microstructure level between the segments of reading texts.

What referred to as macrostructure and microstructure in Chung (2000) was discussed by Degand and Sanders (2002) as local and global levels of coherence. The aim of their study was to investigate the impact of causal discourse markers on the comprehension of expository texts in L1 and L2 and whether L1 or L2 makes a difference in perceiving the relationship between discourse markers and comprehension. Two groups of L1 and L2 learners were given reading texts followed by comprehension questions in both languages where the texts were manipulated with respect to the presence or absence of discourse markers. The study revealed that linguistic markers both signaling phrases and discourse markers help readers in both L1 and L2 to form a coherent cognitive representation of the information in the text, and the presence of causal markers seems to influence the construction of a coherent mental representation at both local and global coherence levels.

Similarly, Geva (1992) supported the positive effect of connectives on coherence and comprehension locally and globally. Geva (1992) designed fill in blank and match tasks to test the signaling of conjunctions at three different levels: intrasentential, intersentential and discourse, and whether every level support the other. She found that the relationships between text segments are scaffolding each other starting with the relation within the sentence to the relation between the sentences that finally lead to coherent representation to the overall discourse. Being able to infer the logical relationships within intrasentential or intersentential constrains is positively related to better information processing in the extended discourse.

In a similar study of discourse markers and intersentensial relationships, Millis and Just (1994) examined whether the presence of discourse markers such as 'because' between two sentences creates the activation of information given in the first sentence. The subjects were given a number of statements pairs some of which include markers and some not and were asked to read them on a computer screen. After reading, the subjects were asked to judge whether the word appeared on the screen is a probe word in the first clause and then answer true-false comprehension questions. The results revealed that discourse markers led to reactivation of contents of the first of two statements to be integrated and the discourse marker versions in the study led to faster recognition time. The subjects were able to integrate the statements into a coherent representation in related statement linked by discourse markers and the presence of markers also increased the integration and the coherence of the eventual sentence representation.

\section{B. On-line and Off-line Coherence}

Discourse markers aid inferences that could be drawn from the text, which serve to relate parts of the text to each other for integrating the information given (Dijk \& Kintsch, 1983). The issue of the inference from physical representation of the text to the cognitive construction of information resulted in distinguishing between on-line and offline coherence, and in questioning whether the coherence on-line would lead to the coherence off-line. Sanders and Noordman (2000) investigated the role of coherence relations assumed to be built by discourse markers in text processing and they examined the explicit and implicit inferences of these relations; i.e. whether coherence relations have cognitive relevance or not. The participants were given manipulated reading texts, some have markers and some have not, where some express causal relations while other express list relations. The reading activities were followed by verification and recall tasks. The results showed that the markers have an effect during online processing, but its influence decreases over time, and the processing of a text segment depends on the relation it has with preceding segments in the text. Discourse markers facilitate the encoding of the coherence relation between two text segments and the presence of markers leads to faster processing of the subsequent segment.

The inference of physical text scripts in text coherence was also studied by Noordman, Vonk, and Kempff (1992). They examined the understanding of 'because' sentences in context, and whether off-line information representation is affected by inference process of such marker, which is assumed to relate part of the text to a previous part and in this way establish on-line coherent representation. In one of the experiments where the participants were given different short reading texts with and without the marker 'because' followed by true false questions, Noordman et al. were testing whether readers make inferences of the causality relation implicitly or explicitly. Results revealed that these inferences are not spontaneously made on-line. Besides, the reader's purpose affects the on-line inference process especially when readers want to obtain certain information concerning a particular point. These inferences are actually backward and not necessarily on-line but rather off-line.

On the other hand, Millis, Graesser, and Haberlandt (1993), in a study that investigated the impact of discourse markers on memory for expository text, argued that discourse markers negatively interfere on the process of recall which is the main process in structuring coherent representation of information. Same manipulated texts, with and without discourse markers, were given to the participants who were asked to recall the information of the text after reading. The results of the study showed that recall for passages without discourse markers was higher than the recall for passages with markers. Discourse markers did not facilitate memory, which is basic for comprehension, quite the opposite, they reduced or constrained the degree to which the reader generates inter-clause elaborations which causes fragmented cognitive representation of text information.

In sum, whether markers have negative or positive or even no effect at all on reading comprehension has yet to be resolved in the literature. Therefore, more studies are needed to determine the effect of discourse markers on the comprehension of text information. Accordingly, this paper, following most of the studies mentioned above, tests the 
hypothesis that discourse markers have an effect on reading comprehension and the following question will be examined in this paper:

Does the presence of discourse markers facilitate reading comprehension?

\section{METHOD}

\section{A. Participants}

The participants in this study were ten international students from different countries (5 Saudi, 3 Chinese, 1 Korean, and 1 Vietnamese). They were all studying English in an intensive English program at a southwest university in the United States. All participants are in the intermediate level of the program where they were placed after they had taken the TOEFL language proficiency test. This group was chosen to control for proficiency variability had the participation been also open to other learners with different proficiency levels in the program and to have a homogeneous group to a large extent. The participants were 7 males and 3 females with no substantial differences between their ages $(\mathrm{M}=20.2$; $\mathrm{r}=5$; $\mathrm{SD}=1.68$ ). However, there were clear differences in the number of years they had learned or had been exposed to English language before $(\mathrm{M}=11.7 ; \mathrm{r}=12 ; \mathrm{SD}=4.32)$.

\section{B. Design}

The study employs a control group design to test the hypothesis that discourse markers facilitate reading comprehension. The independent variable was discourse markers and reading comprehension was the dependent variable. Learners were assigned to matched groups based on their reading placement test scores. In a matched group design, learners are matched based on a criterion (e.g., proficiency level, L1 background, number of years studying English...etc). In this study the criterion was English language proficiency level based on the placement test results. For example, if two students got a score of 8 out of 10 on the placement test, they would form a pair and one of them will be assigned to the control group and the other will be assigned to the experiment group randomly. This process resulted in five pairs and they were divided into two groups. Half of the learners, therefore, $(\mathrm{N}=5)$ were assigned to the control group and the other half of the learners $(\mathrm{N}=5)$ were assigned to the experiment group. Moreover, the matching procedure resulted in uneven distribution of learners by L1 background or gender. This is usually expected in such procedure, but it made the investigation of L1 or gender effect, in this study, almost impossible.

The same experiment text was manipulated into two versions, one included discourse markers, to be taken by the control group, and the other did not, to be taken by the experiment group. An interview was designed, too, to get the personal background information and to have the participants' comments on the experiment test.

\section{Materials}

\section{a. Reading placement test}

The reading placement test consisted of one expository text of approximately 300 words followed by 6 comprehension questions. The text was chosen from an intermediate level academic reading skill textbook - Making Connection (Pakenham, 2005). The book was designed for students who want to improve their reading skill ability to get the required score in the TOEFL, hence the text was chosen from this book as to avoid the difficulty that might arise from the difference between the level of the students and the level of the placement text. Although the topic of the text Heart Disease and Changing Attitudes (Pakenham, 2005, p. 8) was believed to be quiet common and familiar to the participants, the questions tested the information given or inferred only from the text. The comprehension questions, which were all text based, consisted of 2 true or false and 4 multiple-choice questions.

b. Experimental test

The experiment text was chosen from Cambridge Preparation for the TOEFL Test designed and constructed by experts working in this field. The text, which is an actual text used in the standardized globally administered exam TOEFL, is of approximately 300 words followed by 8 comprehension questions. To avoid prior knowledge or information variable on the test material, the topic of the chosen text was of historical information about using wood in North American and European colonies, a topic which is or likely to be unfamiliar to international students. The text was manipulated to create two versions, one actual text and text with discourse markers absent. The actual text consisted of 5 discourse markers ( 2 order markers: secondly and thirdly, 3 compare and contrast markers: nevertheless, but and however) whereas these markers were omitted from the second version of the text. Under working definition of discourse markers in this study, these were the markers found in this text which as mentioned above was suitable for its uncommon topic to the participants. The subordinate conjunctions such as because and but were not omitted from the text as they were not functioning as discourse markers in their contexts. Instructions of the test were to read the text and underline any word, phrase or sentence where the participants face difficulty and then to answer the questions followed. The two versions were followed by 8 multiple-choice comprehension questions about the text information.

Questions in both the placement and the experiment reading passages were used as is, were not modified, and no other questions were added in order to maintain the validity of the reading passages questions.

c. Interview

The interview consisted of two main parts (see Appendix A). The first included questions about the personal information of the participants such as age, gender, and English study background. The second part was the main part 
which included six reflective open-answer questions. The questions ranged from general questions about the text and the reading activity to specific questions about the underlined phrases or sentences in participants' collected reading materials.

\section{Procedure}

The study was carried out over an 8-day period. First, on day one of the procedure, in a regularly scheduled reading class, the participants were given the placement test to answer in 20 minutes. Based on the placement test scores the participants were divided into two matched groups. On day eight, in the reading class a week after the placement test, the experiment test was administered. To avoid participants' feelings of having different texts by organizing them into two groups in the class, their names were already written on the test papers which was a usual practice used by the teacher. The participants remained in their seats and given the predetermined version to take the test. Both groups took the test at the same time in class with a 20-minute period of time. The participants were asked to read the text and underline any word, phrase, sentence or group of sentences that they might consider difficult or ambiguous, and then answer 8 multiple-choice questions. The participants asked to submit their test papers to the researcher, who was waiting in the teacher's office next to the class room, and answer his questions. Each participant was interviewed separately for almost five minutes and asked to reflect and comment on the reading activity and the underlines he or she made during the experiment test.

\section{RESUltS}

Two reading texts followed by comprehension questions were used in this study. The first was used as the placement test to measure students reading ability in order to match them and assign them to two matched groups, while the second was used to administer the experiment.

\section{A. Placement Test}

The placement test had a maximum score of 10 points. The participants were paired and assigned to two groups: control and experiment groups. As shown in Table 1., the experiment group $M d n$ was 6.66 while the $M d n$ of the control group score was, also, the same 6.66. Besides, the difference between the $I Q R$ of the two groups was not noteworthy $($ control group $=3.33$; experiment group $=4.17)$.

TABLE 1

\begin{tabular}{llccc} 
& \multicolumn{5}{c}{ PLACEMENT SCORES BY GROUP } \\
\hline & Median & IQR & $z$ & $p$ \\
\hline $\begin{array}{l}\text { Control group } \\
(n=5)\end{array}$ & 6.66 & 3.33 & -1.00 & .317 \\
$\begin{array}{l}\text { Experimental group } \\
(n=5)\end{array}$ & 6.66 & 4.17 & & \\
\hline
\end{tabular}

This showed that there was no difference in the variability of the two groups. Although the data was normally distributed, the number of the subjects was relatively small $(n=10)$. So a Wilcoxon Signed Ranks Test was used to compare their scores. As planned, there was no significant differences between the two groups $(z=-1.00, p>.05)$. Thus, there were no differences between the two groups in terms of the learners' overall reading comprehension.

\section{B. Experiment Test}

For the experiment test, the total score was also10 points. As shown in Table 2., the scores Mdn of the control group, which read the original text, was 2.50, while the scores $M d n$ of the experiment group, which read the modified text was 3.75. This revealed that there is a slight difference between the medians of the two groups. As to whether there was a significant differences in the performance of the two groups in terms of their scores on the reading comprehension questions, Wilcoxon Test results $(z=-.137, \mathrm{p}>.05)$ indicated that there was no significant difference.

TABLE 2

EXPERIMENT SCORES BY GROUP

\begin{tabular}{|c|c|c|c|c|}
\hline & Median & IQR & $\mathrm{Z}$ & $\mathrm{p}$ \\
\hline $\begin{array}{l}\text { Control group } \\
(n=5)\end{array}$ & 2.50 & 3.75 & -.137 & .891 \\
\hline $\begin{array}{l}\text { Experimental group } \\
(n=5)\end{array}$ & 3.75 & 3.12 & & \\
\hline
\end{tabular}

\section{DISCUSSION}

The results of this study illustrate that the performance of the experiment group was not different from the control group in responding to the reading comprehension questions. On the contrary, they were relatively equal. There was no impact of discourse markers on the reading comprehension of both groups. The facilitative effect of discourse markers on building macro-coherent representation of text information revealed by Chung (2000), and Degand and Sanders 
(2002) was not supported in this study. Moreover, the coherence of text does not seem to follow a build-up hierarchy, shown in Geva (1992) and in Millis and Just (1994).

On the other hand, the interview with the subjects after the experiment test revealed that $90 \%$ of them reported that the test was not too difficult or too easy, while only $10 \%$ reported that the text was relatively hard for them. However, when they were asked about the difficult part of the text, they all reported it was "vocabulary", which was really obvious when the parts they underlined in the text while taking the test were examined. They were asked to underline not only vocabulary but any part in the text that they think it is difficult or confusing, whether a phrase, a sentence or a group of sentences. However, they underlined only vocabulary and reported that they did not feel that there were any confusing parts or missing pieces of information and they reported that the flow of ideas in the text was sound. This finding was reported by all learners and there was not difference by learners who were considered a bit higher than others in the groups.

Although the participants did not understand some vocabulary in the text, they were able to understand the information given in the text and to build a global coherence. Moreover, they did not show any indication that there is any misconnection or no connection at the inter-sentential level, which provides evidence that the presence or absence of discourse markers may not affect the representation of the text information on-line (Noordman, Vonk, \& Kempff,1992) as opposite to the claim that discourse markers facilitate on-line coherence process as well as off-line cohesion process (Sanders \& Noordman, 2000). On the other hand, coherence of text components for off-line unity could be achieved by integrating the pieces of information of the text through the semantic relationships such as anaphora, cataphora, substitution and ellipsis (Halliday \& Hasan, 1976). In this respect, the relationship of discourse markers to text comprehension might just be as the relation of other vocabularies and phrases to the overall understanding of the text. This argument is still awaiting further research and future investigation.

According to the results of this paper, however, the hypothesis presented in previous literature that there is an effect of discourse markers, is not supported at least for the subjects of this study. In addition, this study is just another contribution to the previous literature in respect of showing no inference of discourse markers on the coherent construction of text representation at a global level and adding strength to this theory. However, it could present a new perspective of treating discourse markers as just vocabulary with semantic meaning and function; which needs empirical investigation to be attested. On the other hand, the influence of discourse markers at local level, or in other words 'inter-sentential' (Geva, 1992; Millis \& Just, 1994) can still be valid because, from this paper perspective, at local level a discourse marker would be crucial element as any other vocabulary if taken from a sentence, though this claim is not always true and it calls for more research too.

The results of this study, however, should be treated with caution since the sample of the study is very small. This limitation made it impossible to investigate other possible factors, such as L1 influence and gender, that might have led to such results. Other factors would be language proficiency level. Since only one group of English proficiency levels (i.e., intermediate) was chosen with the rationale that proficiency level needed to be controlled, the investigation of the effect of proficiency level could not be achieved in this study and future research could include different levels of language proficiency to investigate such impact.

\section{CONCLUSION}

In fact, reading comprehension is a complicated process that has to do with a lot of factors regarding background and cognitive processing; the process which is still vague and has no firm explanations to how text is processed. The results of this study contribute to the field of text cognitive processing and discourse markers inference. The effect of discourse markers on overall representation of coherent information for reading comprehension require more investigation and, based on the results of this study, discourse markers could just be treated as other units in the text and could have the impact of any other vocabulary in the text. In other words, learners might be processing discourse markers based on meaning but not function. This claim needs to be investigated in future research and call for reconsidering the relationship between discourse markers and text processing.

\section{APPENDIX A INTERVIEW QUESTIONS}

\section{Part one: Personal Background}

Gender:

Country:

Number of years of studying English before:

Age:

First language:

Part two: Questions

What do you think of the reading task? Is it difficult or easy?

Where did you find it easy or difficult in the text? 
Why did you underline this part of the text?

Do you feel that there is something missing?

Do you feel that there is a flow of the ideas or there is something wrong? If not, what and where?

Do you have another thing to say about the text reading activity?

\section{REFERENCES}

[1] Blakemore, Diane. (1987). Semantic constraints on relevance. Oxford: Basil Blackwell Ltd.

[2] Blakemore, Diane. (2002). Relevance and linguistic meaning. Cambridge: Cambridge University Press.

[3] Chung, Sin L. J. (2000). Understanding signals and reading comprehension. Australian Review of Applied Linguistics, vol. 23, pp. 77-93.

[4] Degand, Liesbeth; Lefèvre, Nathalie \& Bestgen, (1999). The impact of connectives and anaphoric expressions on expository discourse comprehension. Document Design, vol. 1, pp. 39-51.

[5] Degand, Liesbeth \& Sanders, Ted. (2002). The impact of relational markers on expository text comprehension in L1 and L2. Reading and Writing: An Interdisciplinary Journal, vol. 15, pp. 739-757.

[6] Fraser, Bruce. (1990). An approach to discourse markers. Journal of Pragmatics, vol. 14, pp. 383-395.

[7] Fraser, Bruce. (1999). What are discourse markers? Journal of Pragmatics, vol. 31, pp. 931-952.

[8] Geva, Esther. (1992). The role of conjunctions in L2 text comprehension. TESOL Quarterly, vol. 26, pp. 731-717.

[9] Halliday, Micheal A. K. \& Hasan, Ruqaiya. (1976). Cohesion in English. London: Longman.

[10] Loman, Nancy \& Mayer, Richard. (1983). Signaling techniques that increase the understandability of expository prose. Journal of Educational Psychology, vol. 75, pp. 402-412.

[11] Millis, Keith \& Just, Marcel. (1994). The influence of connectives on sentence comprehension. Journal of Memory and Language, 33, 128-147.

[12] Millis, Keith; Graesser, Aurther \& Haberlandt, Karl. (1993). The impact of connectives on the memory for expository texts. Applied Cognitive Psychology, vol. 7, pp. 317-339.

[13] Noordman, Leo; Vonk, Wietske \& Kempff, Henk. (1992). Causal inferences during the reading of expository texts. Journal of Memory and Language, vol. 31, pp. 573-590.

[14] Pakenham, Kenneth. (2005). Making connections: A strategic approach to academic reading. New York: Cambridge University Press.

[15] Sanders, Ted \& Noordman, Leo. (2000). The role of coherence relations and their linguistic markers in text processing. Discourse Processes, vol. 29, pp. 37-60.

[16] Schiffrin, Deborah. (2005). Discourse markers: Language, meaning, and context. In Deborah Schiffrin, Deborah Tannen, \& Heidi Hamilton (eds.), The handbook of discourse analysis, pp.54-75. Oxford: Blackwell Publications Ltd.

[17] Spyridakis, Jan \& Standal, Timothy. (1987). Signals in expository prose. Reading Research Quarterly, vol. 22, pp. $285-298$.

[18] Taboada, Maite. (2006). Discourse markers as signals (or not) of rhetorical relations. Journal of Pragmatics, vol. 38, pp. 567592.

[19] van Dijk, Teun Adrianus \& Kintsch, Walter. (1983). Strategies of discourse comprehension. New York: Academic.

Mansoor Al-Surmi is a PhD Candidate in Applied Linguistics at Northern Arizona University, USA. He is also a faculty member at the English Department, College of Education-Arhab, Sana'a University, Yemen. His research interests include examining the theoretical and practical issues in discourse analysis, corpus linguistics, second language acquisition, and assessment. 